Article

\title{
The Influence of Microstructure on the Mechanical Properties and Fracture Behavior of Medium Mn Steels at Different Strain Rates
}

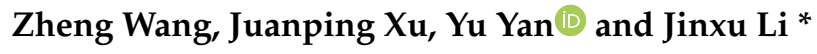 \\ Corrosion and Protection Center, Institute for Advanced Materials and Technology, University of Science and \\ Technology Beijing, Beijing 100083, China; swangzheng@163.com (Z.W.); 18811390215@163.com (J.X.); \\ yanyu@ustb.edu.cn (Y.Y.) \\ * Correspondence: jxli65@ustb.edu.cn
}

Received: 27 November 2019; Accepted: 13 December 2019; Published: 17 December 2019

\begin{abstract}
The primary task of automotive industry materials is to guarantee passengers' safety during a car crash. To simulate a car crash, the influence of strain rates on mechanical properties and fracture behavior of medium Mn steels with different Si content (0Si without $\delta$-ferrite and $0.6 \mathrm{Si}$ with about $20 \%$ $\delta$-ferrite) was conducted using the uniaxial tensile test. The results show that ultimate tensile strength is higher, whereas total elongation is lower in $0 \mathrm{Si}$ than in $0.6 \mathrm{Si}$. As the strain rate increases, ultimate tensile strength and total elongation decrease in both $0 \mathrm{Si}$ and $0.6 \mathrm{Si}$; nonetheless, total elongation of $0.6 \mathrm{Si}$ decreases faster. Meanwhile, the area reduction of $0.6 \mathrm{Si}$ increases as the strain rate increases. The microcrack's number on a rolling direction (RD)-transverse direction (TD) surface is considerably increased; nonetheless, the microcrack's size is restrained in 0.6Si compared with 0Si. Microcracks start at $\gamma\left(\alpha^{\prime}\right) / \alpha$-ferrite interfaces in both $0 \mathrm{Si}$ and $0.6 \mathrm{Si}$, whereas little nucleation sites have also been found at $\left(\gamma\left(\alpha^{\prime}\right)+\alpha\right.$-ferrite $) / \delta$-ferrite boundaries in $0.6 \mathrm{Si}$. Meanwhile, $\delta$-ferrite reveals a higher capacity for microcrack arrest. As the strain rate decreases, increased lower crack growth results in fine and even dimples on fractographs with abundant second cracks on fractographs; meanwhile, the small microcrack's number increases, while the large microcrack's number decreases on an RD-TD surface.
\end{abstract}

Keywords: medium Mn steels; strain rate; $\delta$-ferrite; mechanical properties; fracture behavior

\section{Introduction}

The automotive industry requires materials that not only satisfy the need to be lightweight to meet the demand for energy conservation and environmental protection, but can also withstand impact during a car crash to guarantee the safety of passengers [1,2]. As a third-generation advanced high-strength steel (3rd-generation AHSS), medium Mn steels with a mixture of $\alpha$-ferrite and reverted $\gamma$ [3-5], and medium Mn steels exhibit excellent strength and high ductility owing to the transformation-induced plasticity (TRIP) [6-9]. The TRIP can be influenced by heat treatment [10], chemical composition [11], and cold deformation [12]. In addition to the TRIP effect, dislocation strengthening and refinement strengthening can also influence the mechanical properties in medium Mn steels [13].

Medium Mn steels with Si have been investigated by some researchers [3,14-16], but the purpose of $\mathrm{Si}$ addition has rarely been mentioned. It is well known that $\mathrm{Si}$ and $\mathrm{Al}$ addition can increase the reverted $\gamma$ transition temperature, which can shorten the intercritical annealing time [17]. Si and $\mathrm{Al}$ are the ferrite-forming elements. Hence, $\mathrm{Si}$ and $\mathrm{Al}$ addition can promote the formation of $\delta$-ferrite in medium Mn steels. Si is also an effective solid solution strengthening element [18]. Si addition can be beneficial for the processing and mechanical properties of medium Mn steels [19]. Sun et al. [19] 
reported that total elongation (TEL) reached a maximum value at the addition of $1 \mathrm{wt}$.\% Si, while mechanical properties were worse without the added Si. In addition, plenty of coarse $\delta$-ferrite could be gained at the addition of $3 \mathrm{wt}$ \% Si, resulting in poor mechanical properties [19]. However, Cai et al. [20] obtained the best TEL when the microstructure contained plenty of $\delta$-ferrite, demonstrating that results from different studies are often controversial. Meanwhile, other researchers have shown that $\delta$-ferrite can sustain more strain during deformation owing to the strain partitioning [21,22]. The effect of strain partitioning of $\delta$-ferrite can contribute to the high mechanical stability of reverted $\gamma$ during deformation. However, Sun et al. [19] revealed that the micro-strain of $\delta$-ferrite approximately equals that of $\alpha+\gamma$. Namely, there is no strain partitioning of $\delta$-ferrite.

The fracture behavior of medium Mn steels has been investigated by some researchers. Choi et al. [23] identified void nucleation sites in both the $\delta$-ferrite and the interface of $\delta / \alpha+\gamma$ as nonmetallic inclusions. Void nucleation sites at the interface of $\gamma\left(\alpha^{\prime}\right) / \alpha$ resulted from the strain gradients. The propagation of cracks was observed both within the $\delta$-ferrite and along the $\delta / \alpha+\gamma$ interface parallel to the rolling direction (RD), which is consistent with the analysis by Tonizzo et al. [24]. Although Sun et al. [25] reported the same void nucleation sites, cracks propagated preferentially into the brittle $\delta$-ferrite perpendicular to the RD in both hot and cold rolled 3Si samples. The brittle $\delta$-ferrite resulted from the intermetallic compound of B2 phase. In addition, $\gamma\left(\alpha^{\prime}\right)+\alpha$ layers show a higher capacity for crack arrest in cold-rolled 3Si samples. However, $\delta$-ferrite was considered a soft phase in medium Mn steels [20,21], which contradicts the result of Sun et al. Zhang et al. [26] revealed that the propagation of cracks was slightly deflected when the cracks met the soft $\delta$-ferrite phase. On the basis of these results, the influence of $\delta$-ferrite resulting from the interaction of $\mathrm{Si}$ and $\mathrm{Al}$ on fracture behavior is not yet clear.

Strain rate dependent TRIP effects, mechanical properties, and fracture behavior are vital factors during car crashes. However, the influence of the strain rate on these characteristics in medium Mn steels has been rarely described. Firstly, for TRIP effects and mechanical properties, Li et al. [1] demonstrated that the strain rate strongly influences both the TRIP effect and dislocation slip using the nanoindentation method. The dislocation density and strain-induced martensite increased as the strain rate increased. Cai et al. [27] demonstrated that strain-induced martensite decreased as the strain rate increased using the tensile test, a finding that contrasts the result of $\mathrm{Li}$ et al. It also revealed that the effect of strain rate (ranging from $1 \times 10^{-4} / \mathrm{s}$ to $1 \times 10^{-1} / \mathrm{s}$ ) on flow stress was negligible. The TEL decreases as the strain rate increases. Apparently, the TRIP effects and mechanical properties are not yet clear. Second, although fracture behavior has been studied by some researchers [23-25], the influence of strain rate on fracture behavior in medium Mn steels has not been mentioned. However, the influence of strain rate on fracture behavior has been investigated in TRIP and dual phase (DP) steels [28,29]. Kim et al. [28] revealed that the plastic neck propagates to neighboring locations at a high strain rate in DP 780 and TRIP 780. Namely, the area reduction decreases as the strain rate increases. Furthermore, regardless of the strain rate, the fractographs exhibit small, round dimples. Cao et al. [29] has reported that the area reduction of DP 800 increases as the strain rate increases at room temperature. Apparently, the results of Kim and Cao are contradictory. However, the documented strain rate effects on TRIP and DP steels cannot be perfectly adapted to medium Mn steels because of the complex microstructure and deformation mechanism. Meanwhile, the effect of the strain rate on nucleation and propagation of cracks has not been mentioned for medium Mn steels. Consequently, it is worthwhile to systematically investigate the effect of strain rate on the fracture behavior of medium Mn steels.

In summary, the influence of strain rate and $\mathrm{Si}$ on the mechanical properties and fracture behavior of medium Mn steels is not yet clear. Consequently, the present work aims to investigate the influence of strain rate on the mechanical properties and fracture behavior of $0.2 \mathrm{C}-6 \mathrm{Mn}-3 \mathrm{Al}-(0,0.6) \mathrm{Si}$ medium Mn steels. The method simulates a car crash [30]. 


\section{Materials and Methods}

The chemical compositions of the steels are listed in Table 1, and the steels are labeled as OSi and $0.6 \mathrm{Si}$. Briefly, $21 \mathrm{~kg}$ ingots of the steels were cast in a vacuum induction furnace. The ranges of Ac1-Ac3 for both 0Si and 0.6Si are $678-966^{\circ} \mathrm{C}$ and $677-1005^{\circ} \mathrm{C}$, respectively. Ac1 and Ac3 were calculated by the Thermo-Calc software with a TCFE7 database (provided by the CISRI-TCS Joint Open Laboratory). The ingots were forged into billets with a section dimension of $100 \times 30 \mathrm{~mm}^{2}$ after heat treatment for $2 \mathrm{~h}$ at $120{ }^{\circ} \mathrm{C}$ and air cooling to room temperature (RT). The billets were solution treated for $2 \mathrm{~h}$ at $1200{ }^{\circ} \mathrm{C}$ again, hot-rolled to $4.5 \mathrm{~mm}$ thick plates via six passes at rolling temperatures from approximately $850^{\circ} \mathrm{C}$ to $1150^{\circ} \mathrm{C}$, and then air cooled to RT. Intercritical annealing of both 0Si and $0.6 \mathrm{Si}$ was performed at $740^{\circ} \mathrm{C}$ for $10 \mathrm{~min}$ and $30 \mathrm{~min}$, respectively, obtaining the desired mechanical properties. The samples were then air cooled to RT.

Table 1. The chemical compositions of $0 \mathrm{Si}$ and $0.6 \mathrm{Si}$ (wt.\%).

\begin{tabular}{ccccc}
\hline Samples & C & Mn & Al & Si \\
\hline $0 \mathrm{Si}$ & 0.22 & 6.12 & 3.08 & - \\
$0.6 \mathrm{Si}$ & 0.18 & 6.06 & 2.87 & 0.58 \\
\hline
\end{tabular}

MTS Landmark ${ }^{\circledR}$ (MTS, Eden prairie, MN, USA) servohydraulic test system samples were machined parallel to the rolling direction with a gauge section of $25 \times 5 \times 1 \mathrm{~mm}^{3}$. Uniaxial tensile tests were performed at different strain rates ranging from $10^{-4} / \mathrm{s}$ to $10^{-1} / \mathrm{s}$ at RT. MTS specimens were mechanically polished before the uniaxial tensile tests.

The microstructure of the specimens, which were etched with $4 \%$ nitric acid, was characterized by optical microscopy (OM; Olympus Corporation, Tokyo, Japan). Specimens for electron backscattered diffraction (EBSD; channel 5, Oxford Instruments NanoAnalysis, High Wycombe, UK) measurements were polished mechanically first and then electropolished at RT at a voltage of $25 \mathrm{~V}$ for $25 \mathrm{~s}$. The electrolyte consists of perchloric acid and acetic acid in a ratio of 1:9. The accelerating voltage, working distance, and step of EBSD were $20 \mathrm{kV}, 17 \mathrm{~mm}$, and $60 \mathrm{~nm}$, respectively. Transmission electron microscopy (TEM) analysis was performed using a TECNAI G2 20 (FEI, Hillsboro, OR, USA) at an accelerating voltage of $200 \mathrm{kV}$. TEM specimens were mechanically thinned to $50-80 \mu \mathrm{m}$, and discs with a diameter of $3 \mathrm{~mm}$ were then stamped out. The discs were further thinned using a twinjet electropolisher (RL-1, Rui Ling Chuang Xin, Beijing, China) at $30 \mathrm{~V}$ and $-30{ }^{\circ} \mathrm{C}$ with an electrolyte solution of $5 \%$ perchloric acid and $95 \%$ alcohol. The fractographs and fracture surface of RD-transverse direction (TD) were characterized by a secondary electron microstructure (SEM; Zeiss, sigma300, Oberkochen, Germany).

The X-ray diffraction (XRD; TTRIII, Riguka, Japan) samples underwent continuous scanning at $5^{\circ} / \mathrm{min}$ in the $2 \theta$ range of $40^{\circ}$ to $100^{\circ}$. The volume fraction of reverted $\gamma$ was calculated as follows [31,32]. The dislocation densities of $\alpha$-ferrite and newly generated martensite (NGM) were calculated by the classical method of Williamson-Hall (WH) [33,34]. The specimens were step-scanned at $0.004^{\circ} \mathrm{s}$ for the peaks $(110) \alpha,(200) \alpha,(211) \alpha$, and (220) $\alpha$. Nanoindentation tests (Nano Indenter XP, Keysight Technologies, Germany) were carried out with the cube's corner tip up to a maximum depth of $2000 \mathrm{~nm}$ to measure hardness. The method for producing XRD and nanoindentation specimens was consistent with that used for EBSD specimens.

\section{Results}

\subsection{Microstructure Characteristics}

The influence of Si on the microstructure of medium Mn steel is illustrated in Figure 1, and the specimens were imaged using OM (a-d) and EBSD (e and f). Briefly, OSi consists of submicron reverted $\gamma+\alpha$-ferrite with a hardness of 3.44 GPa (Figure 1a,c,e). However, $0.6 \mathrm{Si}$ possesses a certain fraction 
of coarse-grained $\delta$-ferrite (approximately 20\%) with a hardness of $2.90 \mathrm{GPa}$, which is parallel to the $\mathrm{RD}$ (Figure $1 \mathrm{~b}, \mathrm{~d}$ ) The hardness of submicron reverted $\gamma+\alpha$-ferrite of $0.6 \mathrm{Si}$ is $3.55 \mathrm{GPa}$ (Figure 1f). The morphology of reverted $\gamma$ in both $0 \mathrm{Si}$ and $0.6 \mathrm{Si}$ is mainly lathy (Figure 1e,f).
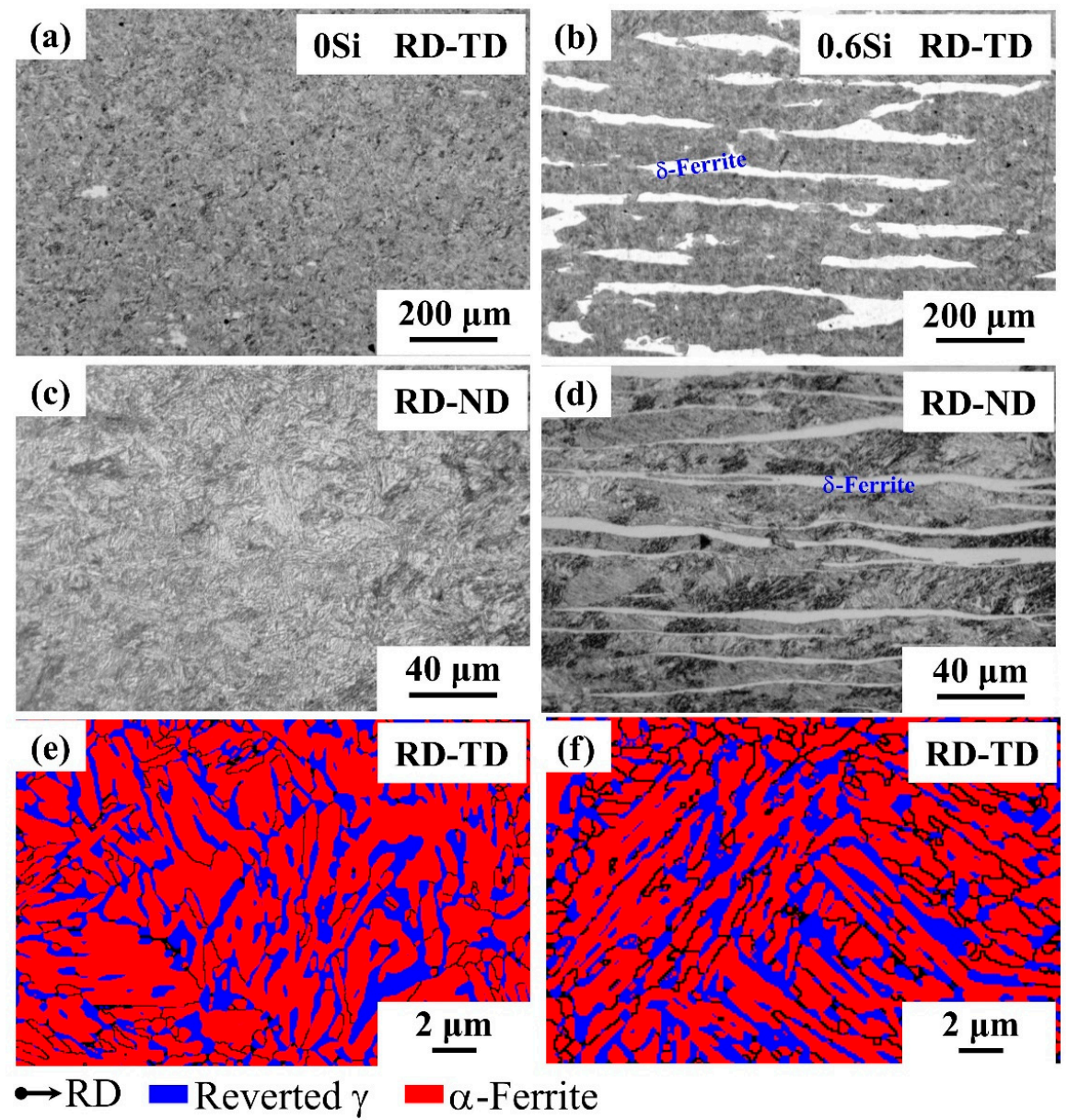

Figure 1. Microstructures of $0 \mathrm{Si}(\mathbf{a}, \mathbf{c}, \mathbf{e})$ and $0.6 \mathrm{Si}(\mathbf{b}, \mathbf{d}, \mathbf{f})$; optical microscopy $(\mathrm{OM})$ microstructures of rolling direction RD-TD (a,b) and RD-normal direction (ND) (c,d) and electron backscattered diffraction (EBSD) microstructure of RD-TD $(\mathbf{e}, \mathbf{f})$. The blue and red phases represent the reverted $\gamma$ and $\alpha$-ferrite, respectively.

The volume fraction (XRD), grain size (EBSD), and the concentration of Mn (TEM-Energy dispersive $x$-ray spectrometry (EDX)) of reverted $\gamma$ in 0Si and 0.6Si are presented in Table 2. No differences in the volume fraction and Mn contents of reverted $\gamma$ for both 0Si and 0.6Si are noted. However, the intercritical annealing time of $0.6 \mathrm{Si}$ extended to $30 \mathrm{~min}$, which resulted in a larger grain size for the reverted $\gamma(280 \mathrm{~nm})$.

Table 2. Detailed information (volume fraction of reverted $\gamma$, Mn concentration in reverted $\gamma$, and grain size of reverted $\gamma$ and $\alpha$-ferrite) for both $0 \mathrm{Si}$ and $0.6 \mathrm{Si}$. XRD, X-ray diffraction; TEM, transmission electron microscopy.

\begin{tabular}{ccccc}
\hline Specimen & Fraction of $\boldsymbol{\gamma}(\%)$-XRD & $\begin{array}{c}\text { Mn Concentration of } \boldsymbol{\gamma} \\
\text { (wt.\%)-EDX (TEM) }\end{array}$ & \multicolumn{2}{c}{ Grain Size (nm)-EBSD } \\
& & $9.2 \pm 0.5$ & $230 \pm 180$ & $\boldsymbol{\alpha}$-Ferrite \\
\hline $0 \mathrm{Si}$ & $35 \pm 2$ & $9.0 \pm 0.5$ & $280 \pm 260$ & $336 \pm 316$ \\
\hline
\end{tabular}




\subsection{Mechanical Properties}

The mechanical properties and strain-induced transformation (SIT) behaviors of both 0Si and 0.6Si are shown in Figure 2. Obviously, the strain rate significantly influences the mechanical properties, especially the TEL (Figure 2a,b). Hence, changing the strain rate is an effective method to control mechanical properties. Figure 2c,d summarize the ultimate tensile strength (UTS), yield strength (YS), and TEL at different strain rates in both 0Si and 0.6Si. Apparently, UTS and YS of OSi are higher than those of $0.6 \mathrm{Si}$, while TEL is lower in OSi than in $0.6 \mathrm{Si}$. As the strain rate increases, UTS of OSi decreases after the initial increase and reaches a maximum $(1000 \mathrm{MPa})$ when the strain rate is $10^{-3} / \mathrm{s}$. With the increasing strain rate, UTS of $0.6 \mathrm{Si}$ and TEL in both $0 \mathrm{Si}$ and $0.6 \mathrm{Si}$ decrease continuously, and YS in both OSi and $0.6 \mathrm{Si}$ increase slightly. Figure 2e displays the transformation ratio of reverted $\gamma$ in both $0 \mathrm{Si}$ and $0.6 \mathrm{Si}$, which shows a similar downtrend as the strain rate increases. The similar downtrend represents an increase in the stability of reverted $\gamma$ and a similar stability of reverted $\gamma$ at the same strain rate. The work hardening (WH) rate at different strain rates in both 0Si and 0.6Si is shown in Figure 2f,g. Regardless of the strain rate, WH decreases quickly at the stage of elastic strain. As shown in Figure 2f, WH shows a monotonic decrease after yield until fracture at strain rates of $10^{-1} / \mathrm{s}$ and $10^{-2} / \mathrm{s}$. However, $\mathrm{WH}$ consists of another stage, which is characterized by a fluctuation of $\mathrm{WH}$ after a monotonic decrease at strain rates of $10^{-3} / \mathrm{s}$ and $10^{-4} / \mathrm{s}$. This phenomenon represents a dramatic SIT, which can postpone necking and promote a large TEL. This fluctuation is increasingly noted as the strain rate decreases. In addition, the intensity of the fluctuation corresponds to the flow stress (magnified in Figure 2a). We determined a critical strain value, $\varepsilon_{\mathrm{c}}$, at which a shift from continuous flow stress to jerky flow stress is noted during deformation. During the mutation, martensite transformation was activated. The $\varepsilon_{\mathrm{c}}$ is lowest when the strain rate is $10^{-4} / \mathrm{s}$. No shift is noted at strain rates of $10^{-1} / \mathrm{s}$ and $10^{-2} / \mathrm{s}$. Regarding the WH rate of $0.6 \mathrm{Si}$, there is an additional stage (indicated by the black arrows in Figure $2 \mathrm{~g}$ ) controlled by the $\delta$-ferrite that can sustain more microscopic strain than macroscopic strain [21,35]. The residual $\mathrm{WH}$ of $0.6 \mathrm{Si}$ is similar to that of $0 \mathrm{Si}$, which is mainly related to the influence of strain rate on reverted $\gamma$ stability.

In general, the strain rate has a great influence on the mechanical properties of steel. The ratio of UTS ( $\left.R_{\mathrm{UTS}}\right)$ and TEL $\left(\mathrm{R}_{\mathrm{TEL}}\right)$ at different strain rates to those at a strain rate of $10^{-1} / \mathrm{s}$ and the area reduction in both $0 \mathrm{Si}$ and $0.6 \mathrm{Si}$ were investigated (Figure 3). Regardless of the Si content, $\mathrm{R}_{\mathrm{UTS}}$ and $\mathrm{R}_{\mathrm{TEL}}$ decrease as the strain rate increases (Figure $3 \mathrm{a}, \mathrm{b}$ ). $\mathrm{R}_{\mathrm{UTS}}$ is almost the same in both 0Si and 0.6Si, whereas $\mathrm{R}_{\mathrm{TEL}}$ is higher in $0.6 \mathrm{Si}$ than in 0Si, showing that TEL decreases faster in 0.6Si than in 0Si as the strain rate increases. As shown in Figure 3c, the area reduction of OSi is independent of the strain rate. However, the area reduction of $0.6 \mathrm{Si}$ increases as the strain rate increases. The results strongly suggest that $\delta$-ferrite promotes heterogeneous deformation in the neck region as the strain rate increases. Meanwhile, the area reduction is lower in 0.6Si than in $0 \mathrm{Si}$, except when the strain rate is $10^{-1} / \mathrm{s}$. 

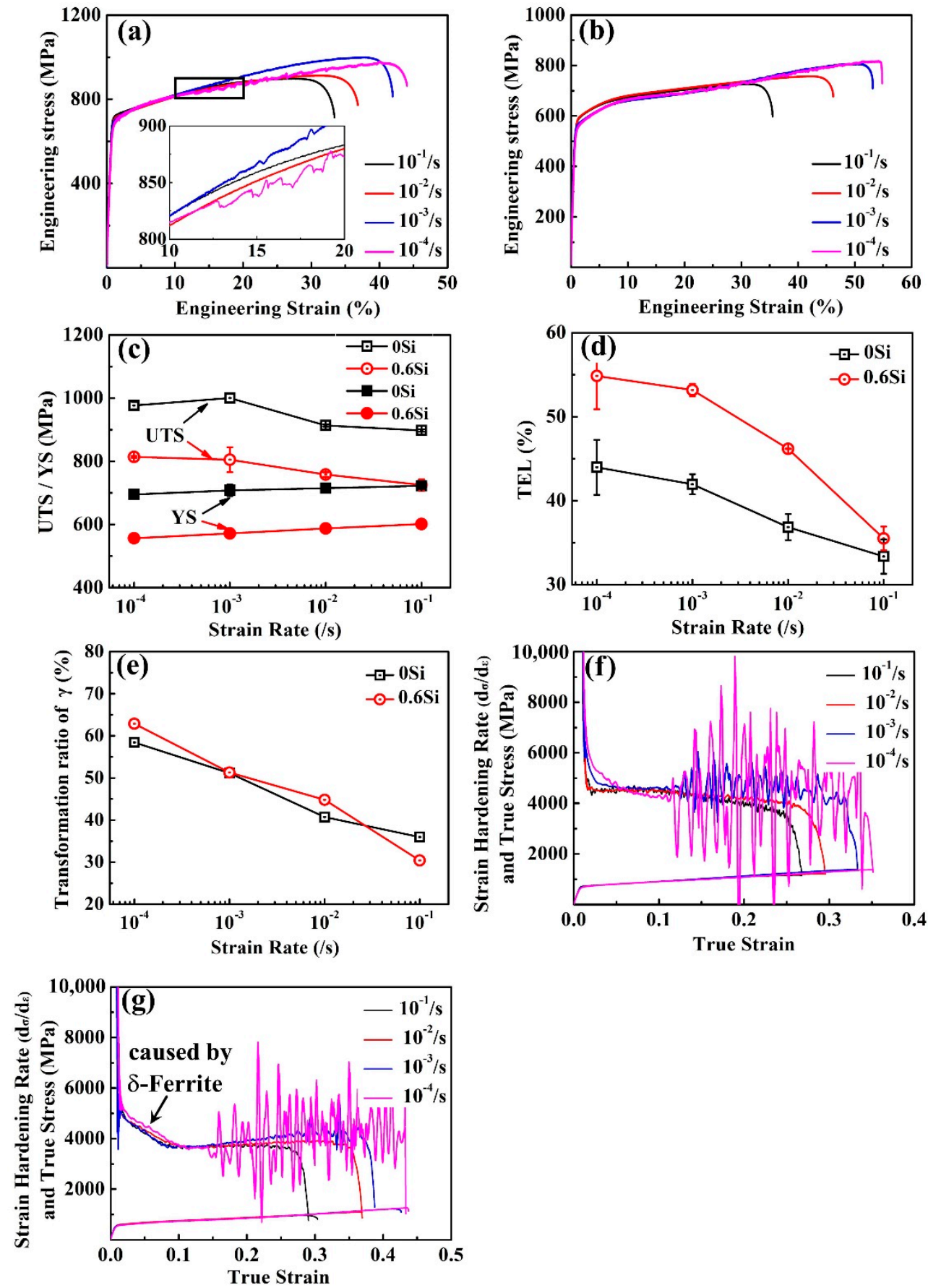

Figure 2. The stress-strain curves of $0 \mathrm{Si}$ (a) and 0.6Si (b); ultimate tensile strength (UTS) and yield strength (YS) (c), total elongation (TEL) (d), and reverted $\gamma$ transformation ratio (e) at different strain rates in both $0 \mathrm{Si}$ and $0.6 \mathrm{Si}$; the true stress-true strain curves and strain hardening rate curves of $0 \mathrm{Si}$ (f) and 0.6Si (g). 

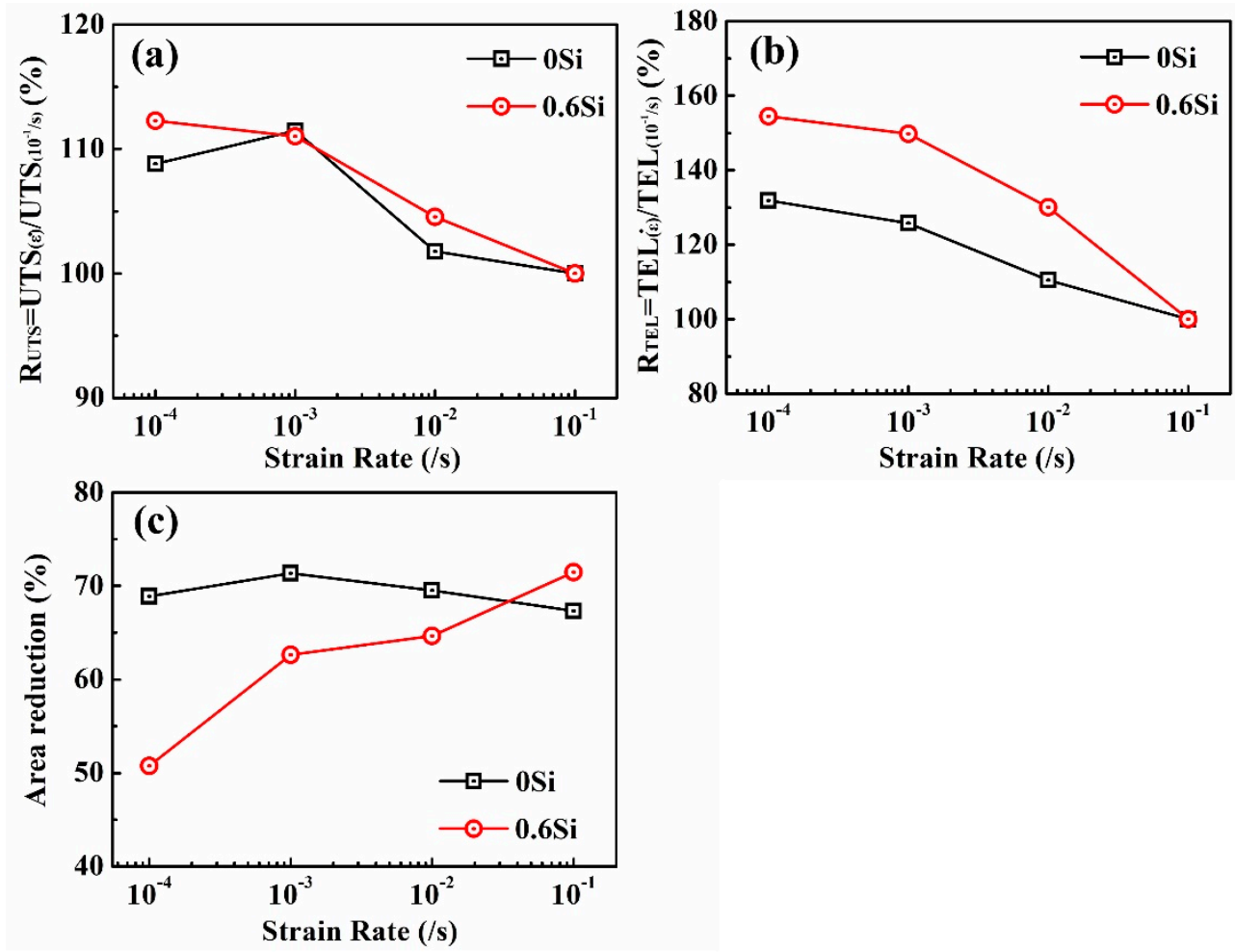

Figure 3. The ratios of UTS (RUTS) (a) and TEL (RTEL) (b) at different strain rates compared to the ratios at a strain rate of $10^{-1} / \mathrm{s}$ vs. strain rates and the area reduction (c) vs. strain rates.

\subsection{Microstructure Evolution}

TEM observation was used to analyze the influence of strain rate on microstructure evolution. For both $0 \mathrm{Si}$ and $0.6 \mathrm{Si}$, the morphology of reverted $\gamma$ and $\alpha$-ferrite is mainly lathy. Meanwhile, undeformed microstructures note minimal dislocations (Figure 4a,b). Deformed microstructures of 0Si at strain rates of $10^{-1} / \mathrm{s}$ and $10^{-4} / \mathrm{s}$ are shown in Figure $4 \mathrm{c}, \mathrm{e}$, respectively. Regardless of the strain rate, the fractured samples express a high density of dislocations. Deformed microstructures of $0.6 \mathrm{Si}$ at strain rates of $10^{-1} / \mathrm{s}$ and $10^{-4} / \mathrm{s}$ are shown in Figure $4 \mathrm{~d}, \mathrm{f}$, respectively. Apparently, regardless of the strain rate, the dislocation density is much higher in $0.6 \mathrm{Si}$ than in $0 \mathrm{Si}$, and the dislocation density is slightly higher in $0.6 \mathrm{Si}$ at a strain rate of $10^{-1} / \mathrm{s}$. These results strongly indicate that the deformed microstructure of reverted $\gamma+\alpha$-ferrite is similar, except for the higher dislocation density in $0.6 \mathrm{Si}$.

Compared with $0 \mathrm{Si}$, it is worthwhile to investigate the microstructure evolution of $\delta$-ferrite in $0.6 \mathrm{Si}$ at different strain rates. As shown in Figure 5a, undeformed microstructures exhibit few dislocations. Figure $5 b$ shows the selected area electron diffraction (SAED) of the area within the red circle in Figure 5a. Although deformed microstructures represent severe dislocation pileup at different strain rates, there are still differences between Figure $5 c-h$. As shown in Figure $5 c$, the dislocation pile-up is more uneven than that in Figure 5f. To investigate the dislocation distribution in detail at the different strain rates, local magnified maps were analyzed (Figure $5 \mathrm{~d}, \mathrm{e}, \mathrm{g}, \mathrm{h}$ ). Apparently, the dislocation distribution on one side of the grain boundary (GB) (area I) is more uneven in Figure $5 \mathrm{~d}$ than in Figure $5 \mathrm{~g}$. For the dislocation interior of $\delta$-ferrite grains, the results reveal that the dislocation distribution is still uneven at a strain rate of $10^{-1} / \mathrm{s}$ (area II in Figure 5e). As shown in Figure 5h, the dislocation sites distributed and piled up homogeneously at a strain rate of $10^{-4} / \mathrm{s}$. In summary, a significant local dislocation pile-up is formed, resulting in an uneven dislocation distribution in $\delta$-ferrite as the strain rate increases. 


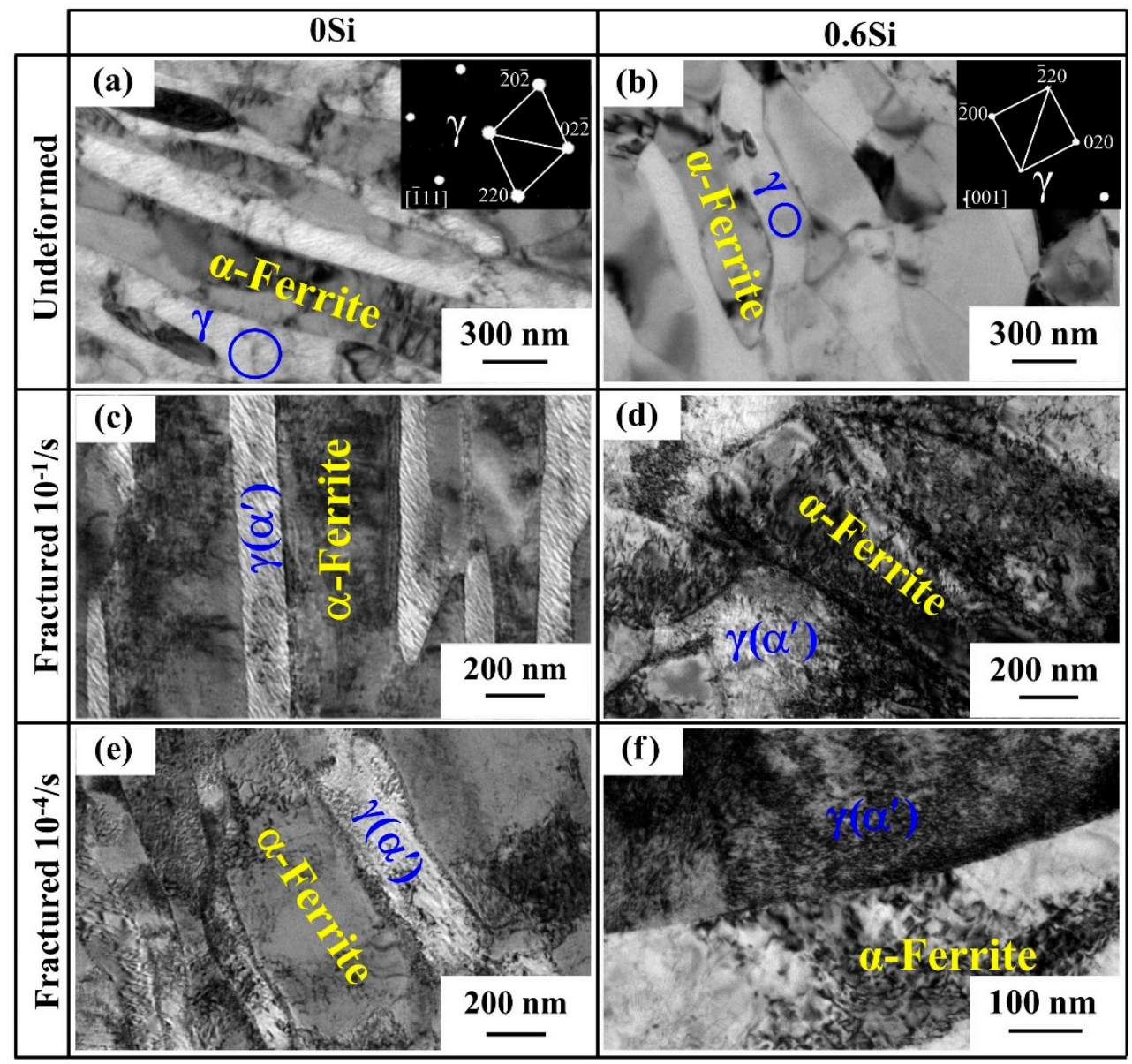

Figure 4. Transmission electron microscopy (TEM) observation of reverted $\gamma+\alpha$-ferrite for both 0Si and $0.6 \mathrm{Si}$; 0Si $(\mathbf{a}, \mathbf{c}, \mathbf{e}), 0.6 \mathrm{Si}(\mathbf{b}, \mathbf{d}, \mathbf{f})$; undeformed $(\mathbf{a}, \mathbf{b})$ and deformed microstructure of fractured specimens (c-f) at different strain rates: $10^{-1} / \mathrm{s}(\mathbf{c}$ and $\mathrm{d})$ and $10^{-4} / \mathrm{s}(\mathbf{e}, \mathbf{f})$.

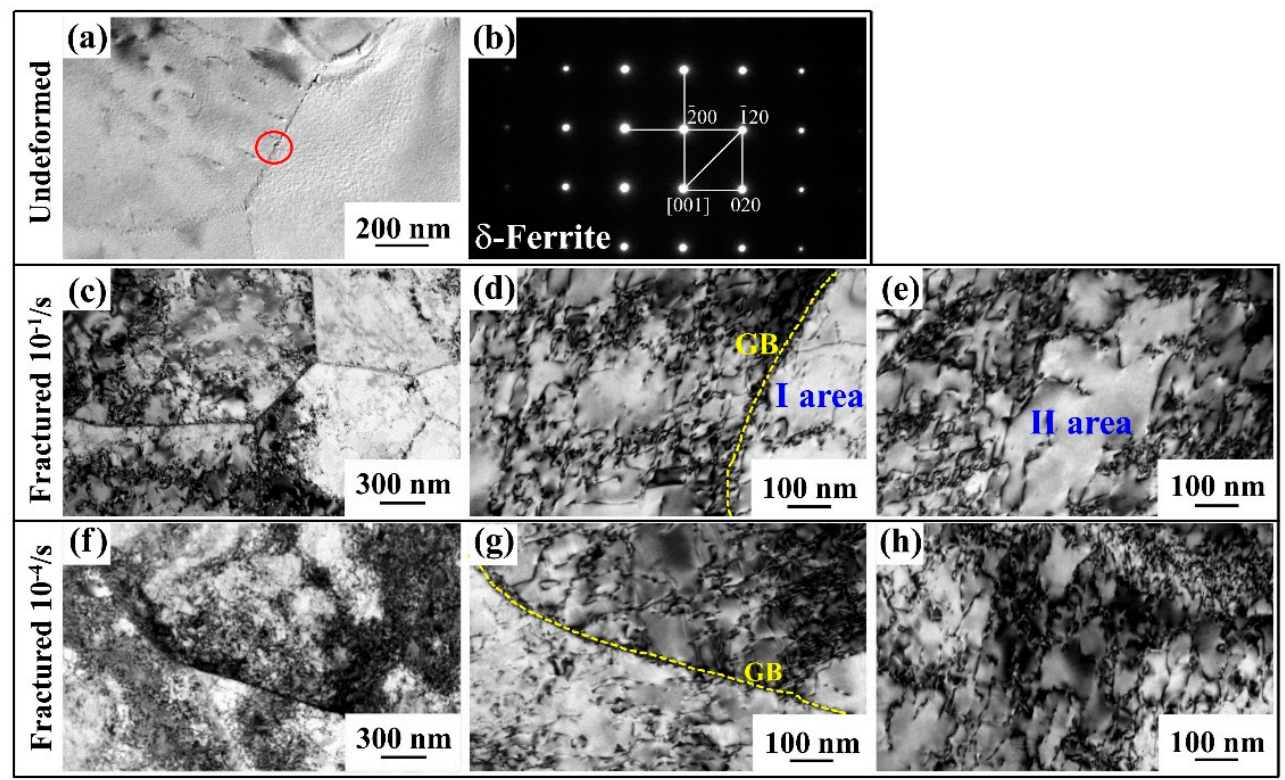

Figure 5. TEM observation of $\delta$-ferrite in 0.6Si: undeformed microstructure (a), electron diffraction spot of selected area (black circle in a) (b), and deformed microstructure of fractured specimens (c-h) at different strain rates, $10^{-1} / \mathrm{s}(\mathbf{c}-\mathbf{e})$ and $10^{-4} / \mathrm{s}(\mathbf{f}-\mathbf{h})$. 
To quantitatively explore the relationship between the dislocation density and the strain rate, XRD analyses of fractured $0 \mathrm{Si}$ and $0.6 \mathrm{Si}$ were conducted. As shown in Figure 6, the dislocation density increases as the strain rate increases, and the dislocation density is higher in $0.6 \mathrm{Si}$ than in 0Si after fracture, which is consistent with the results in Figure 4. The Orowan equation [36] reveals that the velocity of dislocation motions increase as the strain rate increases. According to the theory of classical mechanics, short-range resistance increases as the velocity of dislocation motions increase [36,37], which results in a significant local dislocation pile-up (Figure 5c-e). Consequently, the dislocation density increases as the strain rate increases. The major deformation mechanism of OSi is SIT. In addition to SIT, $0.6 \mathrm{Si}$ consists of plenty of $\delta$-ferrite, and the deformation mechanism of $\delta$-ferrite is dislocation glide owing to the high stacking fault energy (Figure 5). Meanwhile, the TEL is higher in 0.6Si than in 0Si (Figure 2d). Therefore, the dislocation density of $0.6 \mathrm{Si}$ is higher than that of 0Si after fracture.

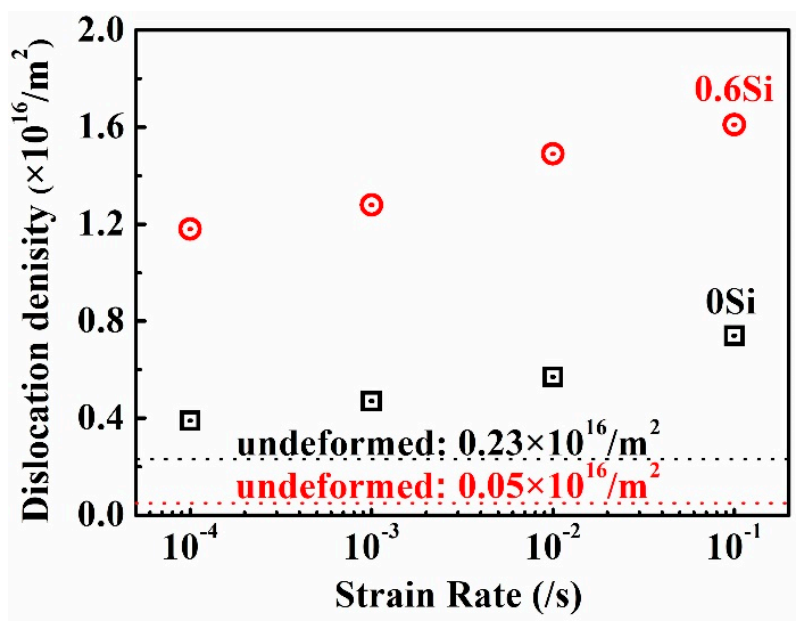

Figure 6. The dislocation density of fractured specimens of both $0 \mathrm{Si}$ and $0.6 \mathrm{Si}$ at different strain rates; the black and red dotted lines represent the dislocation densities of undeformed 0Si and 0.6Si, respectively.

\subsection{Fracture Behavior}

To investigate the behavior of the steel at different strain rates, fractographs of both OSi and 0.6Si were observed by SEM (Figure 7). Regardless of the strain rate, 0Si undergoes obvious necking (Figure 7a1,b1), while the area reduction is independent of the strain rate (Figure 3c). However, as shown in Figure 7c1,d1, the necking trend for $0.6 \mathrm{Si}$ increases as the strain rate increases, which is consistent with the trend of area reduction (Figure 3c). For both $0 \mathrm{Si}$ and $0.6 \mathrm{Si}$, the number of second cracks increases as the strain rate decreases. Meanwhile, there are more second cracks in 0.6Si than $0 \mathrm{Si}$ when the strain rate is $10^{-4} / \mathrm{s}$. Although the specimens exhibit ductile fractographs characterized by dimples at different strain rates, some differences are noted (Figure 7a2-d2). The size of the dimples, characterized by diameter and depth, is large and uneven when the strain rate is $10^{-1} / \mathrm{s}$ (Figure 7a2,c2). Nevertheless, dimple size tends to decrease and is well proportioned at a strain rate of $10^{-4} / \mathrm{s}$ (Figure $7 \mathrm{~b} 2, \mathrm{~d} 2$ ).

Figure 8 shows the cross-sectional (RD-TD) SEM images for both 0Si and 0.6Si at different strain rates. The specimens were directly etched after fracture. The image in the bottom left corner is a local magnification area. As shown in Figure 8a, 0Si consists of some large microcracks (yellow circles) vertical to the RD and a few small microcracks at the interface of $\gamma\left(\alpha^{\prime}\right) / \alpha$-ferrite (red circles) at a strain rate of $10^{-1} / \mathrm{s}$. As shown in Figure $8 \mathrm{~b}$, the number and size of large microcracks decrease (yellow circles that are magnified in the top right corner). However, small microcracks are similar to those of Figure 8a (red circles) when the strain rate is $10^{-4} / \mathrm{s}$. The number of microcracks is considerably increased in $0.6 \mathrm{Si}$ compared with 0Si (Figure $8 c, d$ ). There are many large microcracks (yellow circles) with a few small microcracks (red circles) at a strain rate of $10^{-1} / \mathrm{s}$ (Figure 8c). As shown in Figure $8 \mathrm{~d}$, numerous 
small microcracks (red circles) with a few large microcracks (yellow circles) are noted at a strain rate of $10^{-4} / \mathrm{s}$. Clearly, although the strain rate affected the relative number of large and small microcracks, the nucleation and propagation of microcracks are almost the same.
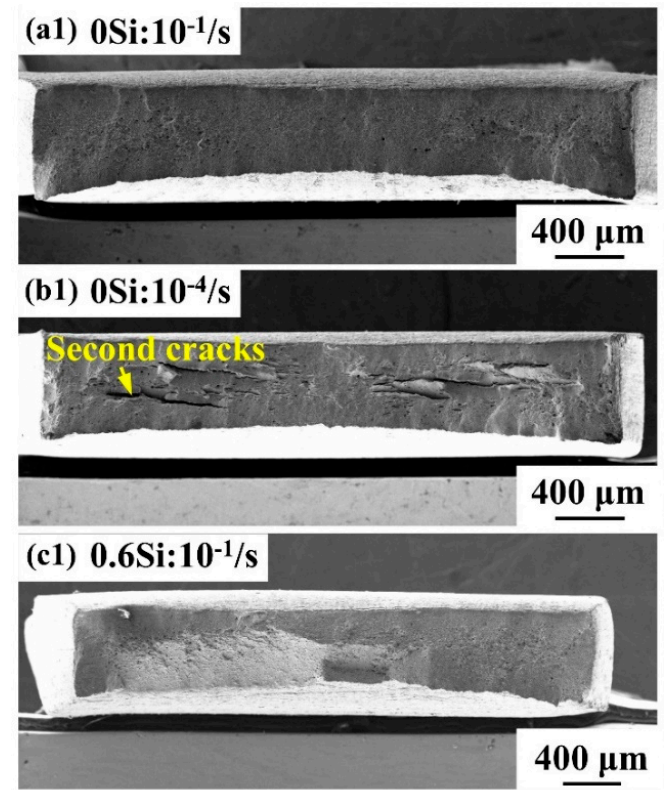

(d1) $0.6 \mathrm{Si}: 10^{-4} / \mathrm{s}$

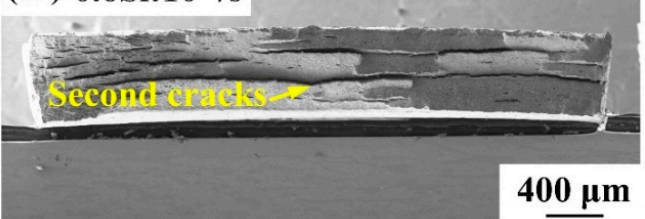

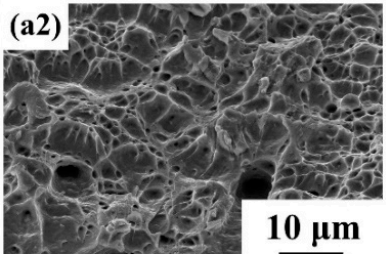
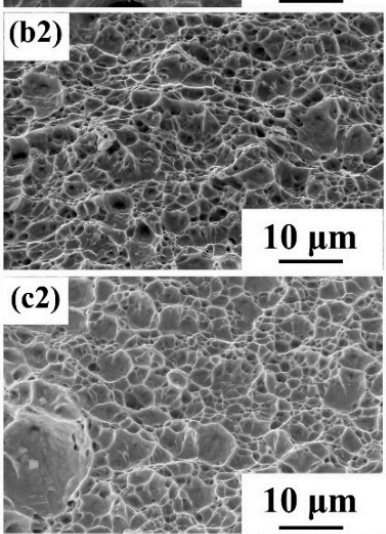

(d2)

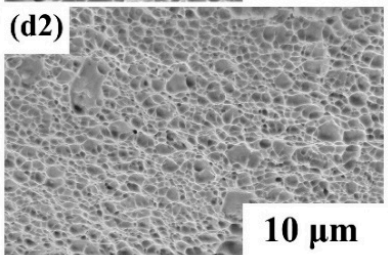

Figure 7. Fractographs at different strain rates, $10^{-1} / \mathrm{s}(\mathbf{a}, \mathbf{c})$ and $10^{-4} / \mathrm{s}(\mathbf{b}, \mathbf{d})$ for $0 \operatorname{Si}(\mathbf{a}, \mathbf{b})$ and $0.6 \operatorname{Si}(\mathbf{c}, \mathbf{d})$; macroscopic fractographs $(\mathbf{a} 1, \mathbf{b} 1, \mathbf{c} 1, \mathbf{d} 1)$, and locally magnified fractographs $(\mathbf{a} 2, \mathbf{b} 2, \mathbf{c} 2, \mathbf{d} 2)$.
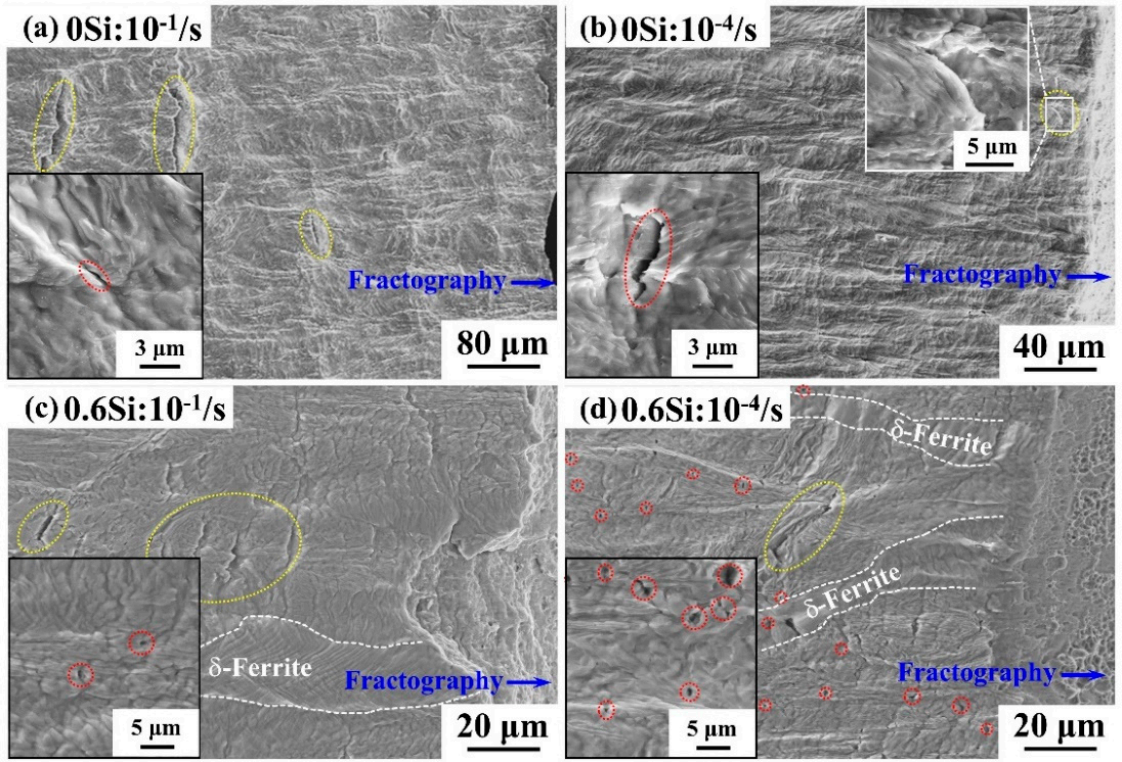

Figure 8. The morphology of the surface of RD-TD at different strain rates, $10^{-1} / \mathrm{s}(\mathbf{a}, \mathbf{c})$ and $10^{-4} / \mathrm{s}(\mathbf{b}, \mathbf{d})$ for 0Si $(\mathbf{a}, \mathbf{b})$ and $0.6 \mathrm{Si}(\mathbf{c}, \mathbf{d})$. The image in the bottom left corner represents a local magnification area. The red circles represent small cracks and the yellow circles represent large cracks. 
To investigate the influence of Si on the nucleation and propagation of microcracks, Figure 9 reveals the results of the fractured cross sectional (RD-TD) SEM investigation in both 0Si and 0.6Si. The specimens were first mechanically polished and then etched after fracture. As shown in Figure 9a, the yellow arrows represent the nucleation sites of microcracks. Apparently, the interfaces of $\gamma\left(\alpha^{\prime}\right) / \alpha$-ferrite are the major nucleation sites of microcracks in 0Si. For 0.6Si, two nucleation sites were investigated: the interfaces of $\gamma\left(\alpha^{\prime}\right) / \alpha$-ferrite (Figure $\left.9 b\right)$ and the boundaries of $\left(\gamma\left(\alpha^{\prime}\right)+\alpha\right.$-ferrite)/ $\delta$-ferrite (Figure 9c). Statistical results reveal that most of the microcrack nucleation sites are located in the phase of $\gamma\left(\alpha^{\prime}\right)+\alpha$-ferrite. Microcrack propagation continued in the phase of $\gamma\left(\alpha^{\prime}\right)+\alpha$-ferrite. However, microcrack arrest occurs, extending to soft $\delta$-ferrite (Figure $9 \mathrm{~d}$ ). Next, microcracks propagated into the soft $\delta$-ferrite, which contributes to the failure of $0.6 \mathrm{Si}$ (Figure 9e).

On the basis of these investigations, the cracking behavior and failure process of $0.6 \mathrm{Si}$ can be proposed as follows: (a) firstly, microcracks nucleate at the interfaces of $\gamma\left(\alpha^{\prime}\right) / \alpha$-ferrite; (b) secondly, microcracks propagate in the phase of $\gamma\left(\alpha^{\prime}\right)$ and $\alpha$-ferrite; (c) thirdly, when the microcracks reach the soft $\delta$-ferrite, the microcracks can be arrested; and (d) finally, the microcracks continue to accumulate and grow in the phase of $\gamma\left(\alpha^{\prime}\right)$ and $\alpha$-ferrite until propagating to the soft $\delta$-ferrite. The repetition of this process contributes to the fracture of $0.6 \mathrm{Si}$.
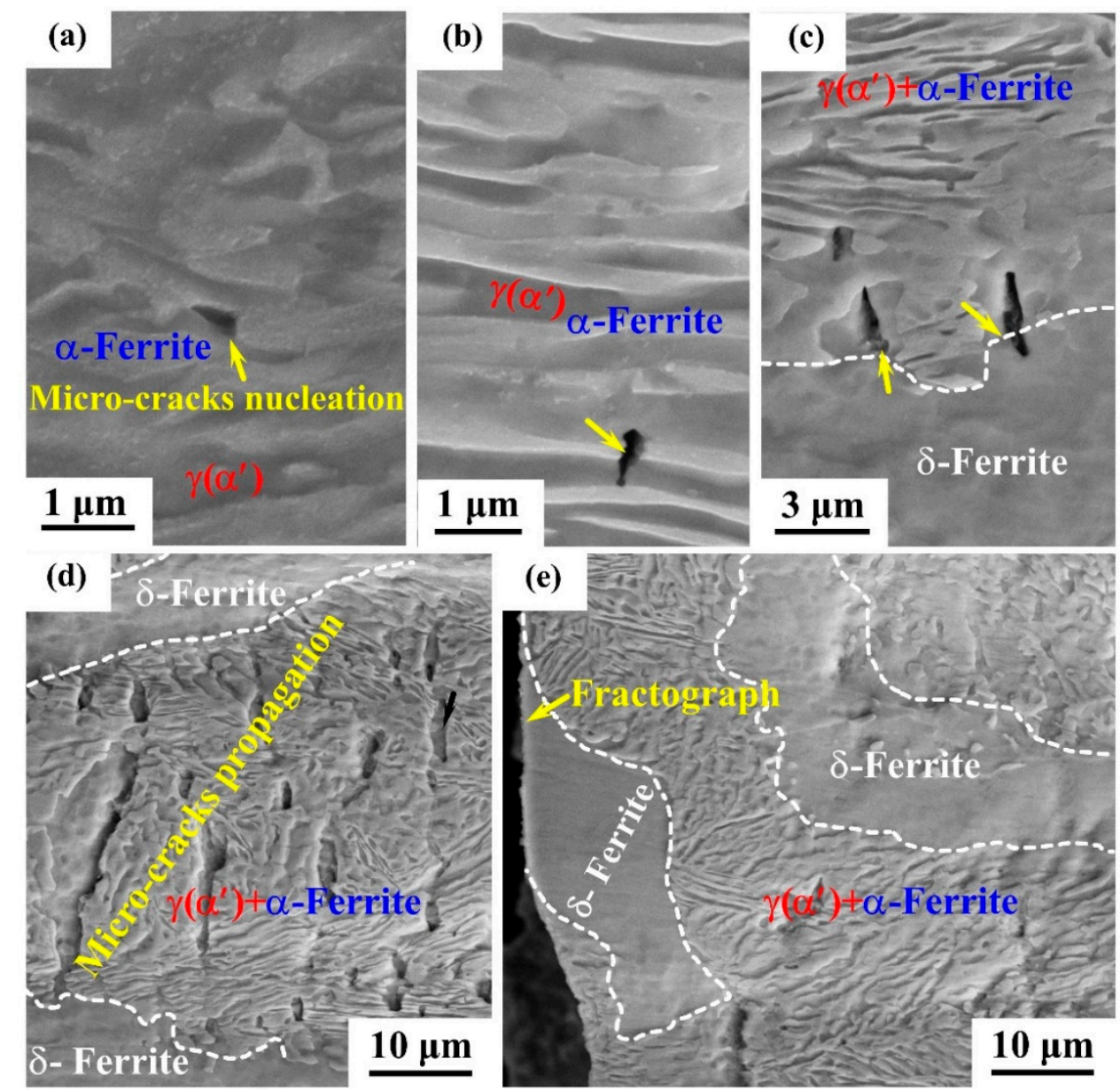

Figure 9. The nucleation and propagation of cracks on the sample's surface of RD-TD at a strain rate of $10^{-4} / \mathrm{s}$ for $0 \mathrm{Si}(\mathbf{a})$ and $0.6 \mathrm{Si}(\mathbf{b}-\mathbf{e})$. The black arrows in $(\mathbf{a}-\mathbf{c})$ represent the nucleation sites of microcracks. 


\section{Discussion}

\subsection{The Influence of Si}

\subsubsection{Microstructure}

It is known that $\mathrm{C}$ and Mn can stabilize austenite, whereas Al and Si can stabilize ferrite [17]. Apparently, the formation of $\delta$-ferrite is promoted as the Al/Si content increases [19,20]. Sun et al. [19] revealed that $3 \mathrm{wt} . \%$ Si added to $0.2 \mathrm{C}-10 \mathrm{Mn}-3 \mathrm{Al}-(0-3) \mathrm{Si}$ steel resulted in a large fraction of $\delta$-ferrite, while there was no $\delta$-ferrite at the addition of $1 \mathrm{wt}$ \% $\mathrm{Si}$. Xu et al. [38] reported almost the same microstructure for $0.18 \mathrm{C}-6.4 \mathrm{Mn}-2.8 \mathrm{Al}-0.5 \mathrm{Si}$ steel, whose chemical composition was similar to that of $0.6 \mathrm{Si}$. Consequently, the relative amounts of $\mathrm{C}, \mathrm{Mn}, \mathrm{Al}$, and Si elements play a crucial role in the microstructure of medium Mn steels. Both Xu et al. [38] and Sun et al. [39] have reported that $\delta$-ferrite could be retained from the hot rolling stage and suffered from recrystallization and growth during intercritical annealing. Compared with the microstructure of 0Si, 0.6Si possesses a certain fraction of coarse-grained $\delta$-ferrite. Consequently, $3 \mathrm{wt} . \% \mathrm{Al}$ cannot contribute to the formation of the $\delta$-ferrite in $0 \mathrm{Si}$, and the additions of $0.6 \mathrm{wt} . \% \mathrm{Si}$ and $3 \mathrm{wt} . \% \mathrm{Al}$ could result in plenty of $\delta$-ferrite.

\subsubsection{Mechanical Properties}

As shown in Figure 2c,d, in general, UTS is higher in 0Si than in 0.6Si, while TEL is lower in OSi than in 0.6Si. For UTS, the components of the strengthening of 0Si and 0.6Si mainly consist of dislocation strengthening, phase transformation strengthening, and refinement strengthening during deformation [13]. As shown in Figure 6, the dislocation density is higher in 0.6Si than in 0Si after fracture. Namely, dislocation strengthening is not the primary strengthening mechanism. Consequently, the remaining factors affecting UTS are phase transformation strengthening and refinement strengthening. To simplify analysis of the effect of Si on mechanical properties, both UTS and the instantaneous hardening index (n) were investigated at a strain rate of $10^{-4} / \mathrm{s}$. Although UTS is much higher in 0Si than in $0.6 \mathrm{Si}$ (Figure 10a), values of $\mathrm{n}$ are almost the same for 0Si and 0.6Si (Figure 10b). These results indicate that phase transformation strengthening is almost the same in both 0Si and 0.6Si during deformation, which is consistent with the results in Figure 2e. Apparently, in addition to submicron-grained reverted $\gamma$ and $\alpha$-ferrite, $0.6 \mathrm{Si}$ possesses plenty of coarse-grained $\delta$-ferrite (approximately 20\%). However, the microstructure of OSi is submicron-grained reverted $\gamma$ and $\alpha$-ferrite. As shown in Figure 10a, YS is much higher in 0Si than in 0.6Si. On the basis of the Hall-Petch equation, it is inferred that refinement strengthening is a major factor resulting in higher YS and UTS in 0Si than in 0.6Si. In addition, the presence of soft $\delta$-ferrite can increase TEL of 0.6Si [20].
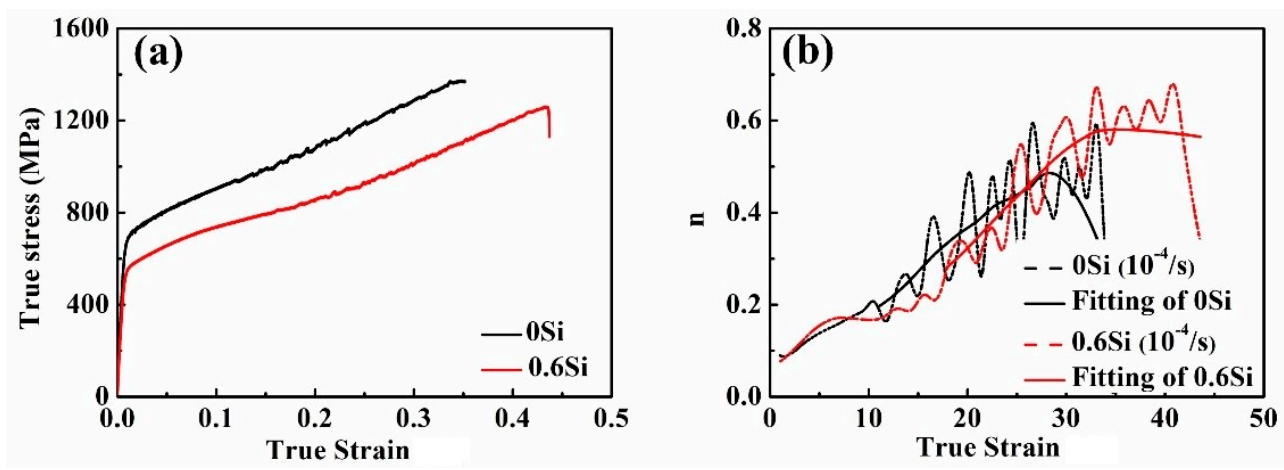

Figure 10. True stress vs. true strain (a) and the instantaneous hardening index (n) vs. true strain (b) in both 0 Si and $0.6 \mathrm{Si}$ at a strain rate of $10^{-4} / \mathrm{s}$. 


\subsubsection{Fracture Behavior}

As shown in Figure 8, regardless of the strain rate, the number of microcracks is considerably increased in $0.6 \mathrm{Si}$ compared with 0Si. The results in Figure 9a reveal that the microcracks of 0Si nucleate at the interfaces of $\gamma\left(\alpha^{\prime}\right) / \alpha$-ferrite, which is similar to the findings of Sun et al. [25]. Nucleation of microcracks can be facilitated by the interface decohesion of $\gamma\left(\alpha^{\prime}\right) / \alpha$-ferrite, which results from the strain gradients [23] and the low toughness of fresh martensite [25]. Microcrack nucleation at the interfaces of $\alpha^{\prime}$ and $\alpha$-ferrite was widely investigated in dual phase steels [40,41]. For 0.6Si, most of the nucleation of microcracks is consistent with that of 0Si. Nevertheless, there are few nucleation sites at boundaries of $\left(\gamma\left(\alpha^{\prime}\right)+\alpha\right.$-ferrite $) / \delta$-ferrite owing to the large plasticity mismatch [23,25]. However, soft $\delta$-ferrite reveals a higher capacity for crack arrest. Although microcracks can nucleate at the boundaries of $\left(\gamma\left(\alpha^{\prime}\right)+\alpha\right.$-ferrite) $/ \delta$-ferrite, the microcracks cannot propagate into the soft $\delta$-ferrite. Microcrack propagation arrest by $\delta$-ferrite results in a smaller crack size in $0.6 \mathrm{Si}$ than in $0 \mathrm{Si}$ at a strain rate of $10^{-1} / \mathrm{s}$. At a strain rate of $10^{-4} / \mathrm{s}$, the microcrack size is much smaller in both $0 \mathrm{Si}$ and $0.6 \mathrm{Si}$, which results from the effect of strain rates. Consequently, $\delta$-ferrite is not a dominant factor in the small microcrack size, leading to similarities in microcrack size for $0 \mathrm{Si}$ and $0.6 \mathrm{Si}$ at a strain rate of $10^{-4} / \mathrm{s}$.

\subsection{The Influence of Strain Rate}

\subsubsection{Ultimate Strength (UTS)}

In general, UTS of both 0Si and 0.6Si increases as the strain rate decreases. As shown in Figure 6, the density of dislocation increases as the strain rate increases. The dislocation strengthening increases as the strain rate increases. As shown in Figure 2e, the ratio of phase transformation decreases, which weakens the phase transformation strengthening as the strain rate increases. The above analysis reveals that dislocation strengthening increases and phase transformation strengthening decreases as the strain rate increases. Hence, competition between the two strengthening mechanisms has a decisive effect on UTS during deformation.

To investigate the competition of strengthening mechanisms during deformation, $\mathrm{n}$ was assessed. For $0 \mathrm{Si}$, the rate of increase in $\mathrm{n}$ is independent of the strain rate at the early stage when the specimens undergo plastic deformation (the red rectangle in Figure 11a). However, as the true strain increases, the three intersections of 1, 2, and 3 revealed that the rate of increase in $n$ increases faster as the strain rate increases (the magnified image of the black rectangle in Figure 11a). Hence, it can be inferred that the rate of dislocation strengthening increases faster as the strain rate increases. However, the rate of increase in $\mathrm{n}$ increases faster as the strain rate decreases when the true strain increases continuously (the three intersections of 4, 5, and 6 in Figure 11a). Consequently, the rate of phase transformation strengthening increases faster when the strain rate decreases. The phenomenon for $0.6 \mathrm{Si}$ is similar to that of $0 \mathrm{Si}$ (Figure 11b). In summary, although dislocation strengthening decreases, phase transformation strengthening is greatly promoted as the strain rate decreases, contributing to the increase of UTS. 

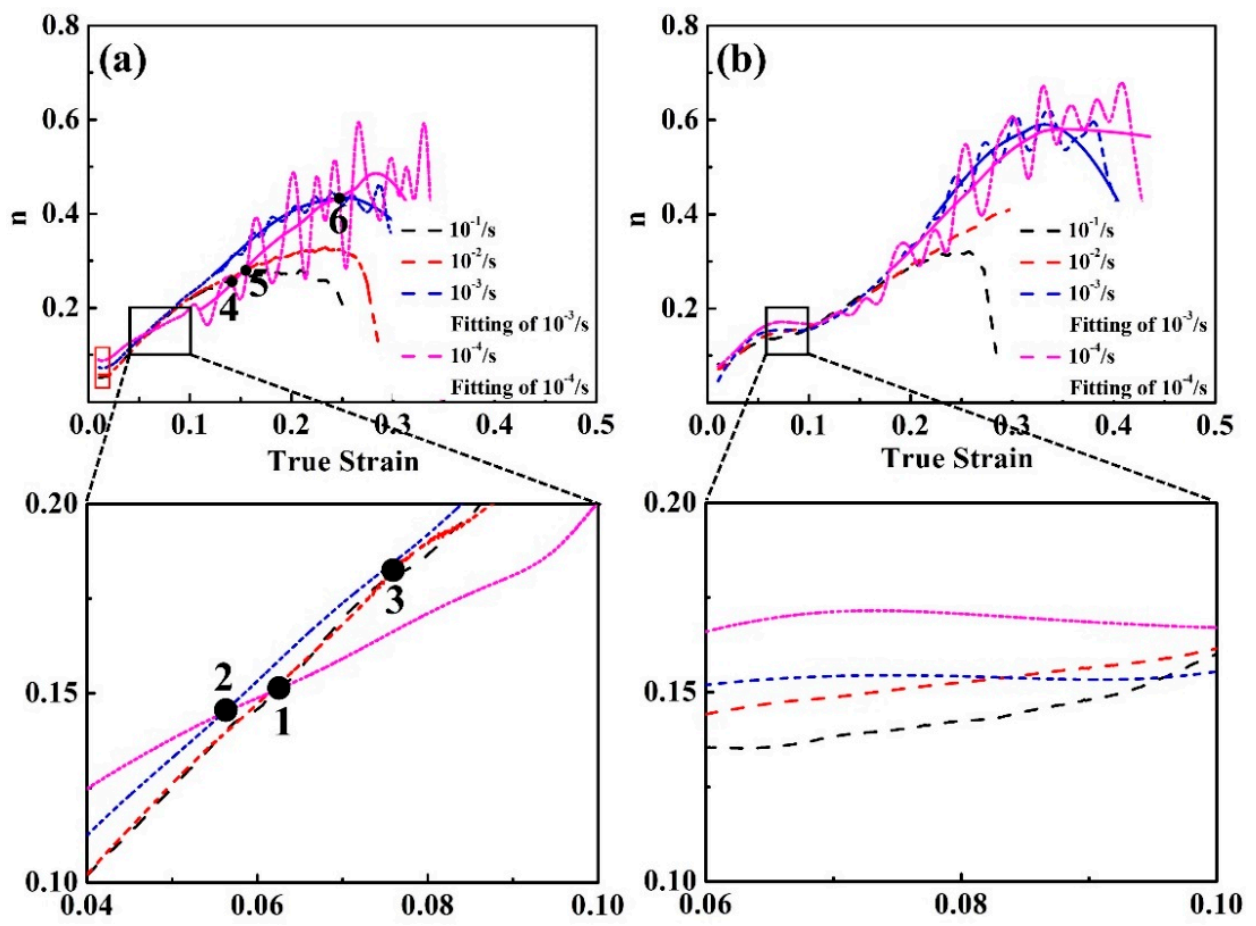

Figure 11. The relationship between the instantaneous hardening index (n) and the true strain at different strain rates of $0 \mathrm{Si}(\mathbf{a})$ and $0.6 \mathrm{Si}(\mathbf{b})$.

\subsubsection{Total Elongation (TEL)}

As shown in Figure 2d, TEL of both 0Si and 0.6Si decreases as the strain rate increases. M.M. Wang et al. [42] reported that sufficient dislocation glide results in a stacking fault that can cause the reverted $\gamma$ to transform into martensite. However, the increase in the short-range resistance makes the mean free path of dislocation decrease, which causes severe local pile-up of the dislocation at a high strain rate. This feature can restrain the interaction of dislocation and the reverted $\gamma$. Hence, the reverted $\gamma$ becomes stable, which can weaken the TRIP effect. This situation promotes the onset of necking, and eventually decreases the TEL continuously as the strain rate increases [43]. As the strain rate increases, the restriction of the strain partitioning effect of $\delta$-ferrite [21], resulting from the local uneven dislocation pile-up (Figure $5 c-e$ ), can further reduce TEL of $0.6 \mathrm{Si}$.

The phase transformation of reverted $\gamma$ could be delayed or stopped if the temperature of the specimens increases $[28,30,44]$. The temperature increase mainly occurs under adiabatic conditions at a high strain rate [29]. The temperature will increase to approximately $60^{\circ} \mathrm{C}$ in adiabatic conditions at a strain rate of $10^{-1} / \mathrm{s}$. The result can both promote the annihilation of dislocation and restrain the phase transformation, limiting the TRIP effect that results in the TEL decrease.

\subsubsection{Fracture Behavior}

The fracture mechanism for engineering materials is the cavity growth mechanism [45]. Stowell [46,47] revealed that cavity growth is mainly controlled by the mechanism of local plastic deformation. The relationship between the rate of cavity growth and plastic deformation is as follows:

$$
\frac{d v}{d t}=\eta v \dot{\varepsilon}
$$

where $v$ is the cavity volume, $\frac{d v}{d t}$ is the rate of cavity growth, $\eta$ is the parameter of $\frac{d v}{d t}$, and $\dot{\varepsilon}$ is the strain rate. The rate of cavity growth increases as the strain rate increases.

As the strain rate decreases, the microstructures of the specimens are relatively homogeneous during deformation, given the regulation of dislocation. The rate of crack growth is reduced; thus, the cavity has 
abundant time to nucleate and, as a result, the dimples are fine and even (Figure $7 \mathrm{~b} 2, \mathrm{~d} 2$ ). Meanwhile, the dramatic TRIP effect promotes the redistribution of stress concentrations. This situation can alleviate the local stress concentration, resulting in an increase in the density of second cracks (Figure $7 \mathrm{~b} 1, \mathrm{~d} 1$ ). Kang et al. [48] also revealed that the formation of delamination on fractographs can promote the occurrence of ductile fracture, contributing to the fine and even dimples at a strain rate of $10^{-4} / \mathrm{s}$.

The number and size of large microcracks on the surface of RD-TD samples decreases as the strain rate decreases (Figure 8). Zhang et al. [26] and Shen et al. [49] demonstrated that delamination could relax the triaxial stress conditions ahead of the advancing crack front. This phenomenon postpones the propagation of microcracks, decreasing the number and size of large microcracks. The number of small microcracks on the surface of RD-TD samples increases as the strain rate decreases. As shown in Figure 2e, the transformation ratio of reverted $\gamma$ increases, which contributes to a rising TRIP effect, delaying the onset of necking as the strain rate decreases [50]. As discussed in 4.1.3, microcracks nucleate at the interface of $\gamma\left(\alpha^{\prime}\right) / \alpha$-ferrite, which results from the strain gradients [23] and the low toughness of fresh martensite [25]. Consequently, more transformation from reverted $\gamma$ to $\alpha^{\prime}$ provides more microcrack nucleation sites as the strain rate decreases.

The area reduction of $0.6 \mathrm{Si}$ increases as the strain rate increases. Namely, $\delta$-ferrite promotes heterogeneous deformation at a high strain rate owing to the local uneven dislocation distribution (Figure $5 \mathrm{c}-\mathrm{e}$ ). It makes the strain rate of the neck region become gradually larger than the initially imposed strain rate.

\section{Conclusions}

The influence of small additions of $\mathrm{Si}$ on the mechanical properties and fracture behavior of medium Mn steels at different strain rates was investigated in detail. The major conclusions are summarized as follows.

(1) The Si addition contributes to about $20 \%$ volume fraction of the coarse-grained $\delta$-ferrite phase in $0.6 \mathrm{Si}$. UTS is higher in $0 \mathrm{Si}$ than in $0.6 \mathrm{Si}$ owing to strong refinement strengthening, whereas TEL is higher in $0.6 \mathrm{Si}$ than in 0Si because of the presence of soft $\delta$-ferrite. As the strain rate increases, UTS and TEL decrease as a result of restriction of the TRIP effect for both 0Si and 0.6Si. Nonetheless, TEL of $0.6 \mathrm{Si}$ decreases faster owing to the additional limitation of the strain partitioning effect of $\delta$-ferrite as the strain rate increases. Meanwhile, the area reduction of $0.6 \mathrm{Si}$ increases owing to the promotion of heterogeneous deformation resulting from $\delta$-ferrite as the strain rate increases.

(2) Regarding the influence of $\mathrm{Si}$ on fracture behavior, $0.6 \mathrm{Si}$ forms more microcracks, but the microcrack size in $0.6 \mathrm{Si}$ is reduced compared with $0 \mathrm{Si}$ on the sample surface (RD-TD). The interfaces of $\gamma\left(\alpha^{\prime}\right) / \alpha$-ferrite are the major nucleation sites of microcracks in both 0Si and 0.6Si. However, there are few nucleation sites at the boundaries of $\left(\gamma\left(\alpha^{\prime}\right)+\alpha\right.$-ferrite $) / \delta$-ferrite in $0.6 \mathrm{Si}$. The propagation of microcracks is promoted in the phase of $\gamma\left(\alpha^{\prime}\right)+\alpha$-ferrite, while the soft $\delta$-ferrite reveals a high capacity for microcrack arrest in $0.6 \mathrm{Si}$.

(3) The influences of strain rate on fracture behavior are as follows. As the strain rate decreases, the drastic TRIP effect and the slower speed of crack growth contribute to fine and even dimples and an increase in second crack density on fractographs for both $0 \mathrm{Si}$ and $6 \mathrm{Si}$. Meanwhile, as the strain rate decreases, on the RD-TD sample surface, the number and size of large microcracks decreased as a result of relaxation of the triaxial stress conditions ahead of the advancing crack front. The relaxation of stress resulted from delamination. The number of small microcracks, on the RD-TD sample surface, increased because of the promotion of the formation of $\alpha^{\prime}$.

Author Contributions: Conceptualization, Z.W. and J.X.; methodology, Z.W. and J.X.; formal analysis, Y.Y. and J.L.; writing—original draft preparation, Z.W.; writing—review and editing, Y.Y. and J.L.

Funding: This research was funded by National Natural Science Foundation of China under Grant Nos. U1760203 and 51571029 and the National Key R\&D Program of China (2017YFB0304401). 
Acknowledgments: Thanks to B.K. for his help.

Conflicts of Interest: The authors declare no conflicts of interest.

\section{References}

1. Li, K.; Injetti, Y.S.Y.; Misra, R.D.K.; Cai, Z.H.; Ding, H. On the Strain Rate Sensitivity of Aluminum-containing Transformation-Induced Plasticity Steels: Interplay between TRIP and TWIP Effects. Mater. Sci. Eng. A 2017, 711, 515-523. [CrossRef]

2. Cai, Z.H.; Ding, H.; Misra, R.D.K.; Ying, Z.Y. Austenite stability and deformation behavior in a cold-rolled transformation-induced plasticity steel with medium manganese content. Acta Mater. 2015, 84, 229-236. [CrossRef]

3. Zou, Y.; Xu, Y.B.; Hu, Z.P.; Gu, X.L.; Peng, F.; Tan, X.D.; Chen, S.Q.; Han, D.T.; Misra, R.D.K.; Wang, G.D. Austenite stability and its effect on the toughness of a high strength ultra-low carbon medium manganese steel plate. Mater. Sci. Eng. A 2016, 675, 153-163. [CrossRef]

4. Chen, J.; Lv, M.Y.; Liu, Z.Y.; Wang, G.D. Combination of ductility and toughness by the design of fine ferrite/tempered martensite-austenite microstructure in a low carbon medium manganese alloyed steel plate. Mater. Sci. Eng. A 2015, 648, 51-56. [CrossRef]

5. Cao, W.Q.; Wang, C.; Shi, J.; Wang, M.Q.; Hui, W.J.; Dong, H. Microstructure and mechanical properties of Fe-0.2C-5Mn steel processed by ART-annealing. Mater. Sci. Eng. A 2011, 528, 6661-6666. [CrossRef]

6. Han, J.; Lee, S.J.; Jung, J.G.; Lee, Y.K. The effects of the initial martensite microstructure on the microstructure and tensile properties of intercritically annealed Fe-9Mn-0.05C steel. Acta Mater. 2014, 78, 369-377. [CrossRef]

7. He, B.B.; Hu, B.; Yen, H.W.; Cheng, G.J.; Wang, Z.K.; Luo, H.W.; Huang, M.X. High dislocation density-induced large ductility in deformed and partitioned steels. Science 2017, 357, 1029. [CrossRef]

8. Wang, M.M.; Tasan, C.C.; Ponge, D.; Raabe, D. Spectral TRIP enables ductile 1.1GPa martensite. Acta Mater. 2016, 111, 262-272. [CrossRef]

9. Lee, H.; Min, C.J.; Sohn, S.S.; Zargaran, A.; Ryu, J.H.; Kim, N.J.; Lee, S. Novel medium-Mn (austenite+martensite) duplex hot-rolled steel achieving $1.6 \mathrm{GPa}$ strength with $20 \%$ ductility by Mn-segregation-induced TRIP mechanism. Acta Mater. 2018, 147, 247-260. [CrossRef]

10. Yang, F.; Luo, H.; Hu, C.; Pu, E.; Dong, H. Effects of intercritical annealing process on microstructures and tensile properties of cold-rolled 7Mn steel. Mater. Sci. Eng. A 2016, 685, 115-122. [CrossRef]

11. Luo, H.; Dong, H.; Huang, M. Effect of intercritical annealing on the Lüders strains of medium Mn transformation-induced plasticity steels. Mater. Des. 2015, 83, 42-48. [CrossRef]

12. Fu, Y.-T.; Liu, J.; Shi, J.; Cao, W.-Q.; Dong, H. Effects of Cold Rolling Reduction on Retained Austenite Fraction and Mechanical Properties of High-Si TRIP Steel. J. Iron Steel Res. Int. 2013, 20, 50-56. [CrossRef]

13. Bellhouse, E.M.; McDermid, J.R. Effect of Continuous Galvanizing Heat Treatments on the Microstructure and Mechanical Properties of High Al-Low Si Transformation Induced Plasticity Steels. Metall. Mater. Trans. A 2010, 41, 1460-1473. [CrossRef]

14. Lee, S.; De Cooman, B.C. Annealing Temperature Dependence of the Tensile Behavior of 10 pct Mn Multi-phase TWIP-TRIP Steel. Metall. Mater. Trans. A 2014, 45, 6039-6052. [CrossRef]

15. Latypov, M.I.; Shin, S.; De Cooman, B.C.; Kim, H.S. Micromechanical finite element analysis of strain partitioning in multiphase medium manganese TWIP+TRIP steel. Acta Mater. 2016, 108, 219-228. [CrossRef]

16. Aydin, H.; Essadiqi, E.; Jung, I.-H.; Yue, S. Development of 3rd generation AHSS with medium Mn content alloying compositions. Mater. Sci. Eng. A 2013, 564, 501-508. [CrossRef]

17. Sun, B.; Fazeli, F.; Scott, C.; Yue, S. Phase Transformation Behavior of Medium Manganese Steels with 3 Wt Pct Aluminum and 3 Wt Pct Silicon During Intercritical Annealing. Metall. Mater. Trans. A 2016, 47, 4869-4882. [CrossRef]

18. Jeong, K.; Jin, J.-E.; Jung, Y.-S.; Kang, S.; Lee, Y.-K. The effects of Si on the mechanical twinning and strain hardening of Fe-18Mn-0.6C twinning-induced plasticity steel. Acta Mater. 2013, 61, 3399-3410. [CrossRef]

19. Sun, B.; Fazeli, F.; Scott, C.; Brodusch, N.; Gauvin, R.; Yue, S. The influence of silicon additions on the deformation behavior of austenite-ferrite duplex medium manganese steels. Acta Mater. 2018, 148, 249-262. [CrossRef] 
20. Cai, Z.H.; Cai, B.; Ding, H.; Chen, Y.; Misra, R.D.K. Microstructure and deformation behavior of the hot-rolled medium manganese steels with varying aluminum-content. Mater. Sci. Eng. A 2016, 676, 263-270. [CrossRef]

21. Ryu, J.H.; Kim, D.I.; Kim, H.S.; Bhadeshia, H.K.D.H.; Suh, D.W. Strain partitioning and mechanical stability of retained austenite. Scr. Mater. 2010, 63, 297-299. [CrossRef]

22. Seo, C.H.; Kwon, K.H.; Choi, K.; Kim, K.H.; Kwak, J.H.; Lee, S.; Kim, N.J. Deformation behavior of ferrite-austenite duplex lightweight Fe-Mn-Al-C steel. Scr. Mater. 2012, 66, 519-522. [CrossRef]

23. Choi, H.; Lee, S.; Lee, J.; Barlat, F.; Cooman, B.C.D. Characterization of fracture in medium Mn steel. Mater. Sci. Eng. A 2017, 687, 200-210. [CrossRef]

24. Tonizzo, Q.; Gourgues-Lorenzon, A.-F.; Mazière, M.; Perlade, A.; Zuazo, I. Microstructure, plastic flow and fracture behavior of ferrite-austenite duplex low density medium Mn steel. Mater. Sci. Eng. A 2017, 706, 217-226. [CrossRef]

25. Sun, B.; Palanisamy, D.; Ponge, D.; Gault, B.; Fazeli, F.; Scott, C.; Yue, S.; Raabe, D. Revealing fracture mechanisms of medium manganese steels with and without delta-ferrite. Acta Mater. 2019, 164, 683-696. [CrossRef]

26. Zhang, Y.; Hui, W.; Wang, J.; Lei, M.; Zhao, X. Enhancing the resistance to hydrogen embrittlement of Al-containing medium-Mn steel through heavy warm rolling. Scripta Mater. 2019, 165, 15-19. [CrossRef]

27. Cai, M.H.; Zhu, W.J.; Stanford, N.; Pan, L.B.; Chao, Q.; Hodgson, P.D. Dependence of deformation behavior on grain size and strain rate in an ultrahigh strength-ductile Mn-based TRIP alloy. Mater. Sci. Eng. A 2016, 653, 35-42. [CrossRef]

28. Kim, J.H.; Kim, D.; Han, H.N.; Barlat, F.; Lee, M.G. Strain rate dependent tensile behavior of advanced high strength steels: Experiment and constitutive modeling. Mater. Sci. Eng. A 2013, 559, 222-231. [CrossRef]

29. Cao, Y.; Karlsson, B.; Ahlström, J. Temperature and strain rate effects on the mechanical behavior of dual phase steel. Mater. Sci. Eng. A 2015, 636, 124-132. [CrossRef]

30. Talonen, J.; Hänninen, H.; Nenonen, P.; Pape, G. Effect of strain rate on the strain-induced $\gamma \rightarrow \alpha^{\prime}$-martensite transformation and mechanical properties of austenitic stainless steels. Metall. Mater. Trans. A 2005, 36, 421-432. [CrossRef]

31. Xu, H.F.; Zhao, J.; Cao, W.Q.; Shi, J.; Wang, C.Y.; Wang, C.; Li, J.; Dong, H. Heat treatment effects on the microstructure and mechanical properties of a medium manganese steel (0.2C-5Mn). Mater. Sci. Eng. A 2012, 532, 435-442. [CrossRef]

32. Wang, C.Y.; Shi, J.; Cao, W.Q.; Dong, H. Characterization of microstructure obtained by quenching and partitioning process in low alloy martensitic steel. Mater. Sci. Eng. A 2010, 527, 3442-3449. [CrossRef]

33. Williamson, G.K.; Smallman, R.E., III. Dislocation densities in some annealed and cold-worked metals from measurements on the X-ray debye-scherrer spectrum. Philos. Mag. 1956, 1, 34-46. [CrossRef]

34. Williamson, G.K.; Hall, W.H. X-ray Line Broadening from Field Aluminium and Wolfram. Acta Metall. 1953, 1, 22-31. [CrossRef]

35. Furnémont, Q.; Lacroix, G.; Godet, S.; Conlon, K.T.; Jacques, P.J. Critical Assessment of the Micromechanical Behaviour of Dual Phase and Trip-Assisted Multiphase Steels. Can. Metall. Q. 2004, 43, 35-42. [CrossRef]

36. Shen, Y.F.; Jia, N.; Misra, R.D.K.; Zuo, L. Softening behavior by excessive twinning and adiabatic heating at high strain rate in a Fe-20Mn-0.6C TWIP steel. Acta Mater. 2016, 103, 229-242. [CrossRef]

37. Kapoo, R.; Nemat-Nasse, S. Comparison between high and low strain-rate deformation of tantalum. Metall. Mater. Trans. A 2000, 31, 815-823. [CrossRef]

38. Xu, Y.B.; Hu, Z.P.; Zou, Y.; Tan, X.D.; Han, D.T.; Chen, S.Q.; Ma, D.G.; Misra, R.D.K. Effect of two-step intercritical annealing on microstructure and mechanical properties of hot-rolled medium manganese TRIP steel containing $\delta$-ferrite. Mater. Sci. Eng. A 2017, 688, 40-55. [CrossRef]

39. Sun, B.; Aydin, H.; Fazeli, F.; Yue, S. Microstructure Evolution of a Medium Manganese Steel During Thermomechanical Processing. Metall. Mater. Trans. A 2016, 47, 1782-1791. [CrossRef]

40. Maire, E.; Bouaziz, O.; Di Michiel, M.; Verdu, C. Initiation and growth of damage in a dual-phase steel observed by X-ray microtomography. Acta Mater. 2008, 56, 4954-4964. [CrossRef]

41. Landron, C.; Bouaziz, O.; Maire, E.; Adrien, J. Characterization and modeling of void nucleation by interface decohesion in dual phase steels. Scr. Mater. 2010, 63, 973-976. [CrossRef]

42. Wang, M.M.; Tasan, C.C.; Ponge, D.; Kostka, A.; Raabe, D. Smaller is less stable: Size effects on twinning vs. transformation of reverted austenite in TRIP-maraging steels. Acta Mater. 2014, 79, 268-281. [CrossRef] 
43. Han, J.; Lee, S.-J.; Lee, C.-Y.; Lee, S.; Jo, S.Y.; Lee, Y.-K. The size effect of initial martensite constituents on the microstructure and tensile properties of intercritically annealed Fe-9Mn-0.05C steel. Mater. Sci. Eng. A 2015, 633, 9-16. [CrossRef]

44. Lee, M.G.; Kim, S.J.; Han, H.N. Crystal plasticity finite element modeling of mechanically induced martensitic transformation (MIMT) in metastable austenite. Int. J. Plast. 2010, 26, 688-710. [CrossRef]

45. Brooks, C.R.; Choudhury, A. Failure Analysis of Engineering Materials; McGraw-Hill: New York, NY, USA, 2002.

46. Stowell, M.J. Cavity growth in superplastic alloys. Met. Sci. J. 2013, 14, 267-272. [CrossRef]

47. Paton, N.E. Superplastic Forming of Structural Alloys; American Institute of Mining, Metallurgical, and Petroleum Engineers: Englewood, CO, USA, 1982.

48. Kang, J.; Li, C.-N.; Yuan, G.; Wang, G.-D. Improvement of strength and toughness for hot rolled low-carbon bainitic steel via grain refinement and crystallographic texture. Mater. Lett. 2016, 175, 157-160. [CrossRef]

49. Shen, X.J.; Tang, S.; Wu, Y.J.; Yang, X.L.; Chen, J.; Liu, Z.Y.; Misra, R.D.K.; Wang, G.D. Evolution of microstructure and crystallographic texture of microalloyed steel during warm rolling in dual phase region and their influence on mechanical properties. Mater. Sci. Eng. A 2017, 685, 194-204. [CrossRef]

50. Zackay, V.F.; Parker, E.R.; Fahr, D.; Busch, R. The enhancement of ductility in high-strength steels. ASM Trans. Q. 1967, 60, 252-259.

(C) 2019 by the authors. Licensee MDPI, Basel, Switzerland. This article is an open access article distributed under the terms and conditions of the Creative Commons Attribution (CC BY) license (http://creativecommons.org/licenses/by/4.0/). 